\title{
Um modelo sócio-econômico para análise dos votos do partido verde nos municípios paranaenses na eleição presidencial de 2010
}

Ronivaldo Steingraber ${ }^{1}$

Resumo: Este artigo analisa o desempenho do Partido Verde nas eleições presidenciais de 2010 nos municípios paranaenses em função de variáveis sócioeconômicas. O modelo estimado mostra que o PV apresenta melhor desempenho em termos de participação relativa nos votos em municípios com maior renda, grau de urbanização e número de estudantes. Por outro lado, nos municípios com maior participação de gastos em saúde e educação e maior número de eleitores o desempenho é inversamente proporcional.

Palavra-chave: Movimento Ambiental; Voto Verde; Voto Econômico.

JEL: A12; A13; D72.

1 Professor Adjunto do Departamento de Economia da Universidade Federal de Santa Catarina (UFSC).

E-mail: ronivaldo.ufsc@gmail.com 


\title{
A model for social and economic analysis of votes in the green party at cities of Paraná in 2010 presidential election
}

\begin{abstract}
This paper analyses the Green Party performance in the 2010 presidential election in the cities of Paraná on the basis of socio-economic variables. The estimated model shows that PV performs better in terms of relative share of votes in cities with higher income, degree of urbanization, and number of students. On the other hand, in cities with higher share of spending on health and education, and a greater number of voters, the performance is inversely proportional.
\end{abstract}

Key-words: Environmental Movements; Green Voting; Economic Voting.

JEL: A12; A13; D72.

\section{Introdução}

O desempenho do Partido Verde (PV) na eleição presidencial de 2010 foi o maior de sua recente história. Engajado na defesa de uma agenda ambiental, este desempenho mostra o amadurecimento do eleitorado brasileiro. Este artigo busca evidências que expliquem esta mudança no perfil do eleitor, por meio da análise de fatores sócio-econômicos no desempenho do PV na eleição presidencial de 2010 nos municípios paranaenses.

Historicamente, os partidos verdes nasceram de movimentos ambientais nos anos 80, herdeiros natos de movimentos sociais dos anos sessenta e setenta. A ascensão destes partidos pode ser explicada pela preocupação ambiental do eleitorado nos países desenvolvidos. O perfil destes eleitores era de renda e educação mais elevadas. Neste sentido, os partidos verdes se beneficiaram de um eleitorado mais politizado e exigente, preocupado com as questões ambientais amplamente divulgadas na mídia e academia. O nível educacional maior (relacionado diretamente com a renda maior) permitia a estes eleitores a formação de uma opinião mais crítica frente aos problemas ambientais. Desta forma, percebe-se uma diferenciação sócio-econômica no eleitorado simpatizante dos partidos verdes.

Esta diferença sócio-econômica, principalmente frente ao nível educacional, sustenta a segunda característica deste eleitor: a desilusão com a política. Os partidos verdes capturaram o voto dos descontentes e indignados com a política tradicional. O nível sócio-educacional mais elevado está relacionado com um grau maior de politização, seja pela urgente causa ambiental, seja pelo desprezo aos métodos tradicionais dos políticos profissionais. O pragmatismo dos partidos verdes e o discurso direto atraíram este eleitorado descontente, além do eleitorado politizado em causas ambientais, de direitos humanos, pacifistas, entre outros. 
O modelo desenvolvido considera variáveis sócio-econômicas dos municípios paranaenses, como a renda per capita, o grau de urbanização, o número de eleitores e de matrículas (estudantes), além do perfil distributivo no município, como o valor dos gastos em saúde e educação e do Índice IPARDES de Desenvolvimento Municipal (IDH/M).

O artigo é composto de duas seções, além desta introdução e da conclusão. A primeira seção apresenta a teoria de base sobre a formação dos partidos verdes a partir dos movimentos sociais e ambientalistas, bem como as características sócio-econômicas e políticas destes partidos. A segunda seção apresenta o modelo econométrico e discute os resultados estimados.

\section{A organização Política e o impacto econômico dos movimentos ambientalistas}

O crescimento dos movimentos de inspiração ambientalista atingiu, segundo Castells (1999: 141), "nos anos 90, 80\% dos norte-americanos e mais de dois terços dos europeus". A grande amplitude deste movimento impôs aos candidatos e partidos a necessidade de inclusão de questões ambientais nas suas agendas públicas.

Todavia, tal debate não restringe à esfera política. Para Castells (1999: 141):

Grandes empresas, inclusive responsáveis por uma grande emissão de poluentes, passaram a incluir a questão do ambientalismo em sua agenda de relações públicas, e também em seus novos e mais promissores mercados. Em todo a mundo, a velha oposição simplista entre os conceitos de desenvolvimento para os pobres e preservação para os ricos tem-se transformado em um debate em diversos níveis acerca da possibilidade real de desenvolvimento sustentado para cada país, cidade ou região. Sem sombra de dúvida, a maioria de nossos problemas ambientais mais elementares ainda persiste, uma vez que seu tratamento requer uma transformação nos meios de produção e de consumo, bem como de nossa organização social e de nossas vidas pessoais.

A organização política dos movimentos ecológicos, denominados posteriormente de "verdes", ganhou perspectiva a partir dos anos sessenta e setenta. Vincent (1995) mostra como os movimentos sociais dos anos sessenta receberam influência da literatura da época, como do livro "Silent Spring (1962), de Rachel Carson. Quase no final da década, The Population Bomb (1968), de Paul Ehrlich e 'Tragedy of the Commons' (1968), de Garret Hardim, evocaram não apenas o espectro do colapso ambiental, mas também sua relação com a superpopulação." (Vicent, 1995: 212).

Mas foi nos anos setenta que a organização política dos movimentos ambientalistas ganhou destaque politicamente em alguns países, como 
Estados Unidos e Alemanha. Neste mesmo período, Vicent (1995: 212) destaca o grande número de textos e relatórios oficiais que enfatizavam os problemas ambientais no mundo industrializado, para o autor:

\begin{abstract}
(..) em vista da atual reação pública a eventos como a crise do petróleo e a relatórios de profunda ressonância, tais como o Global 2000 Report do governo Carter; Uma só Terra (1972), relatório não-oficial da ONU; Os limites do crescimento (1972), do Clube de Roma; o número Blueprint for Survival (1972) do jornal Ecologist e, recentemente, o Relatório Brundtland intitulado Our Common Future (1987). Esses relatórios apresentaram vigorosas razões para que nossa preocupação se concentre no esgotamento total do meio ambiente.
\end{abstract}

Além da contemporaneidade dos movimentos ambientalistas nas últimas décadas do século XX - Castells (1999) estabelece o último quarto do século $\mathrm{XX}$ como à gênese do movimento verde - percebe-se uma ligação entre este movimento e a divulgação de estudos, relatórios e prognósticos de caráter acadêmico/científico para a população, conscientizando a urgência do tema meio ambiente por parte das políticas públicas e a necessidade de mudança da agenda dos governos frente aos problemas divulgados para a sociedade.

Outra característica apontada em Vincent (1995) é a preocupação com os custos da prosperidade, pois os movimentos ambientais (ecológicos) são identificados na década de 1880 a 1890, nos anos 50 e 70. Estes ciclos de preocupação ambiental são derivados do final dos ciclos de crescimento econômico, onde a sociedade apresenta cidadãos com "tempo, educação e segurança financeira para serem capazes de se alarmar com o meio ambiente" (Vicent, 1995: 214).

A organização política dos movimentos ambientalistas acorreu nos anos oitenta. Partidos verdes, como o alemão fundado em 13 de janeiro de 1980, herdaram a mobilização popular de movimentos pacifistas, feministas e antinucleares do final dos anos setenta, com sólida base na liberdade do indivíduo e na democracia, como aponta Castells (1999: 152), estes movimentos de mobilização popular ascenderam politicamente em função do "voto insatisfeito" dos eleitores, "principalmente entre os jovens ${ }^{1}$, aguardando o momento de poder se manifestar" e que não encontravam voz na estrutura rígida dos partidos existentes.

Os partidos verdes mostraram-se pragmáticos, em função da urgência de ação frente ao problema ambiental, fato que sustentou o voto dos insatisfeitos, seja pela agenda de causas sociais que ultrapassavam a questão ambiental, seja pelo desprezo pelos métodos tradicionais de política. Definidos como um partido sem direita ou esquerda, mas para frente, como aponta Rampazzo (2002),

2 Além dos jovens, Castells (1999: 152) aponta os "estudantes, professores e membros de outras categorias bastante distintas dos eleitores relacionados à produção industrial, isto é, desempregados (mas sustentados pelo governo) ou funcionários públicos" como eleitores do Partido Verde alemão. 
ou um antipartido como define Castells (1999), os partidos verdes cresceram rapidamente nos anos oitenta e ganharam espaço político, principalmente no legislativo.

Gore (2008) discute a decepção do eleitor norte-americano com a política. Fato este que pode ser ampliado para os demais países, em menor ou maior grau, pois é uma marca da nova classe média mundial - a geração Y. Para o autor as "pesquisas de opinião mostram que aumenta cada vez mais a aversão pela política como profissão, (...) com o uso de técnicas que manipulam a aparência de sinceridade como recurso para manter prestígio." (Gore, 2008: 152).

Percebe-se um sentimento de insatisfação popular, não apenas com o tema ambiental, mas como os partidos políticos discutem com a sociedade, sem participação do cidadão em tais temas. Neste sentido, assim como nos anos setenta e oitenta, os partidos verdes refletem e captam os interesses de movimentos de insatisfação da sociedade. Os problemas como a corrida nuclear, direitos de minorias, imigração e meio ambiente catapultam os novos eleitores para partidos e agendas políticas participativas e fora do padrão tradicional da "política profissional".

Economicamente, a preocupação de organizações e movimentos ambientais se insere na discussão de desenvolvimento sustentável. Na esfera da Economia existe uma diferença entre desenvolvimento e crescimento econômico. Rampazzo (2002: 164) resume esta preocupação quando discute sobre a necessidade de atitudes pró-ativas da sociedade frente à questão ambiental, para a autora:

\footnotetext{
Sem dúvida, o crescimento econômico é necessário, porém não é suficiente para garantir o desenvolvimento. Deve submeter-se às regras de uma distribuição social equitativa e às imposições ecológicas. Não é possível continuar com um crescimento baseado na utilização extensiva dos recursos naturais. Pode-se e faz-se necessário pensar um crescimento intensivo que utilize de maneira cada vez mais eficaz os recursos. Porém, não pode basear-se total e somente na técnica, mas também na modulação das estruturas de consumo e de estilos de vida.
}

Thomas et al. (2002) demonstram como a crescimento econômico forte, bem como o crescimento lento, nos países em desenvolvimento contribui para a avanço dos problemas ambientais em função do aumento da poluição e da pobreza respectivamente. Neste sentido, o crescimento econômico, conforme a agenda ambientalista, deve incorporar um novo modelo de relação da sociedade com a natureza.

A conscientização da sociedade atual de que o planeta passa por uma crise se dá a partir dos anos 70. Para Rampazzo (2002), três crises se tornam visíveis a partir desta década: a crise tecnológica (esgotamento de padrão de acumulação fordista ou produção em massa), a crise financeira (a crise da desvalorização 
do dólar e a incapacidade dos governos de controlar as suas moedas frente ao processo crescente e instável da globalização) e a crise energética (os choques do petróleo e a dependência de um recurso energético finito).

A agenda do desenvolvimento sustentável é resumida em Sachs (1986) e reflete os problemas identificados nas atuais crises econômica, social e ambiental da sociedade. Para o autor, o desenvolvimento sustentável (não antagônico ao crescimento econômico) deve espelhar: 1) satisfação das necessidades básicas; 2) solidariedade com as gerações futuras; 3) participação da população envolvida; 4) preservação dos recursos naturais e do meio ambiente em geral; 5) elaboração de um sistema social garantindo emprego, segurança social e respeito a outras culturas; 6) programas de educação (Sachs, 2002 apud Rampazzo, 2002: 177).

Esta agenda foi implantada em função da contínua organização da própria sociedade em torno da questão ambiental. Para Vieira (2001) "nas últimas décadas, houve uma expansão na organização ambiental planetária, tanto governamental quanto não-governamental, junto com a explosão mundial de um discurso e comunicação sobre os problemas ambientais" (Vieira 2001: 137). Notícias com destaque na mídia sobre catástrofes naturais, como tsunamis, enchentes e secas alertam as pessoas sobre a urgência do tema meio ambiente, principalmente o aquecimento global, conforme argumenta Nosty (2008).

Castells (1999: 143) analisa a tipologia dos movimentos ambientais e destaca neste a sua "forma de movimento social descentralizado, multiforme, orientado à formação de redes e de alto grau de penetração", o que lhe confere divergências em termos de orientação política, mas aumenta o seu poder de influência junto aos eleitores em função da sua capacidade de conciliar a discurso teórico ao prático de acordo com os mais diversos interesses.

Em outras palavras, o espaço de debate e divulgação das questões ambientais foi ampliado na mídia ${ }^{2}$, na academia, nos governos e na própria sociedade civil organizada, o que representa um poder de pressão política forte na atual sociedade e um ponto central na agenda dos políticos e movimentos políticos. Vincent (1995: 215) aponta um paradoxo nesta relação. Para o autor a conscientização ambiental é derivada da formação de "(...) mudanças econômicas, de classes e profissionais na industrialização avançada” e que se posicionam contrárias aos custos ambientais do crescimento econômico que lhes beneficiaram. A novidade nos movimentos verdes nas últimas décadas reside na sua busca engajada em movimentos político-eleitorais e não apenas em estudos científicos.

2 Castells (1999) avança a noção de uso da mídia pelos movimentos ambientalistas e mostra como ele se beneficiou em primeira mão do crescimento da internet a seu favor. Movimentos como o Greenpeace se valiam de ações de impacto na mídia para mobilizar as pessoas ao ponto de "existirem reclamações por parte dos políticos e das grandes corporações de que é a mídia, e não os ambientalistas, a grande responsável pela mobilização em torno da questão do meio ambiente." (Castells, 1999: 161). Este argumento vai ao encontro de Nosty (2008), para o autor a cobertura de catástrofes ambientais e a lentidão de ações enérgicas por parte dos políticos, principalmente do governo dos Estados Unidos, reforça o uso da mídia na insatisfação do eleitorado atual. 
Não se discute aqui o conteúdo dos discursos ambientalistas. Diferentes nas suas idéias, estes movimentos pregam desde o fim do Estado industrial, até o engajamento com políticas públicas de um Estado Verde, desde a formação de uma nova comunidade em harmonia com a natureza, até a implantação de reciclagem na vizinhança do cidadão. Na esfera econômica, as idéias vão da restrição ao consumo (livre ou imposto pelo Estado, cujos defensores são classificados como Neomalthusianos), até a implantação de uma Economia Hiper Expansionista, com a defesa de elementos tecnológicos que substituam o atual sistema de produção nocivo ao meio ambiente (Vicent, 1995).

Toffler (2003) comenta estas dicotomias quando afirma que o movimento ambiental é "Esse movimento em prol da sanidade ecológica (...) - um exemplo positivo de pessoas comuns do mundo inteiro conduzindo seus líderes. Empurrando a ecologia para os primeiros lugares da agenda mundial (...) (Toffler, 2003: 397-398). Todavia, “(...) esse movimento também tem uma margem antidemocrática. Ele possui seus defensores de um retorno às trevas." (Toffler, 2003: 398).

O que se visualiza na agenda ambiental é a necessidade de discussão dos atuais problemas ambientais advindos do processo de crescimento econômico. Todavia, como apresentado anteriormente, esta discussão é originada justamente do avanço da própria sociedade que cria tais problemas. Neste sentido, uma sociedade mais rica e educada é fundamental para questionar os problemas ambientais e colocá-los no topo da sua agenda política que se reflete nas eleições, como define Castells (1999: 153), "a preservação da natureza, a busca da qualidade ambiental e uma perspectiva da vida ecológica são idéias do século XIX que, em termos de manifestação, mantiveram-se por muito tempo restritas às elites ilustradas dos países dominantes."

Com esta idéia em mente, mesmo que de forma limitada, busca-se identificar como os eleitores nos municípios paranaenses são sensíveis aos problemas ambientais e como os votos da eleição presidencial de 2010 são capturados pelo Partido Verde (PV) que representa primeiramente o ideal de preservação do meio ambiente e em segunda instância, ele capta o voto descontente dos eleitores engajados socialmente e com maior nível educacional e de renda.

\section{O modelo}

O modelo a ser estimado considera o percentual de votos no Partido Verde nas eleições presidenciais de 2010 por município do Paraná. Os votos no PV representam não apenas simpatia pela causa ambiental, mas também uma mudança na sociedade brasileira. Veiga (2007) mostra que as principais legendas partidárias do Brasil (PT, PSDB, PMDB E PFL/DEM) apresentaram redução do número de eleitores com identificação partidária entre 2002-2006. 
Conforme o autor, o PT foi o partido que mais perdeu eleitores, todavia, os demais não absorveram esta perda. Este cenário é particularmente favorável ao crescimento do PV, sem uma identificação ideológica, mas marcado pelo pragmatismo e a simpatia da defesa do meio ambiente, a estratégia ainda culminou com o lançamento de uma mulher para a presidência do país.

Conforme Bohn (2008) o processo de modernização (industrialização, urbanização, entre outros efeitos) condiz com a idéia de igualdade de gênero, por meio de mudanças nos valores e atitudes. Apesar da simpatia, os eleitores ainda se mostram conservadores na identificação do perfil feminino (perfil condizente com o ideal de mulher). O que leva, segundo Finamore e Carvalho (2006), a mídia alimenta o marketing em torno da figura da mulher candidata, comprometida com ideais sociais, formando um estereotipo. Este processo de escolha é favorecido em relação às pessoas mais novas e com maior escolaridade que tendem a se mostrar menos motivados por escolher a candidato em função do gênero.

$\mathrm{O}$ voto no PV é também uma aproximação com este perfil de eleitor, com maior escolaridade e renda.

Por outro lado, o Brasil amadureceu a escolha do eleitor em função dos atributos pessoais do candidato, como competência e honestidade (Borba, 2005). Esta característica apresenta uma dicotomia. Se por um lado ela favorece o crescimento de candidatos que exibam este perfil desejado, por outro, ele conduz a uma falsa sensação de aproximação do candidato ao eleitor. Conforme Manin et al. (2006) argumentam, a eleição é a escolha de políticas públicas e o balanço do último candidato. O problema é a existência de uma relação agente-principal (desvio de objetivos e falta de informação sobre o governante). Neste sentido, a construção mercadológica do perfil desejado pela população de um candidato pode afastar a discussão sobre questões importantes na definição da nova agenda de políticas públicas.

Carreirão (2004) confirma a hipótese de Balbachevsky e Holzhacker (2004) ${ }^{3}$ de que a eleição de Lula foi mais por descontentamento do governo FHC do que uma guiada duradoura do eleitorado para a esquerda. Em outras palavras,

a vitória do PT foi favorecida pela questão do perfil desejado do candidato do que pela sua plataforma de políticas públicas. Este problema é agravado pelo fato do eleitor brasileiro possuir poucas informações, além do caráter difuso destas informações sobre os candidatos. A imagem a atributos pessoais do candidato influenciam na decisão do eleitor.

3 As autoras mostram que a escolha do eleitor nas eleições presidenciais de 1989, 1994, 1998 e 2002 fora decidida mais por questões psicologias do que racionais, apesar do eleitor considerar uma identidade com o candidato, seu potencial de oposição e sua capacidade administrativa. 
A hipótese do descontentamento e da novidade de uma mulher candidata, envolvida com questões ambientais ajuda o crescimento do PV. Todavia, a principal variável de decisão do eleitor é econômica. Conforme Carreirão (1999) se a economia vai bem, o governo é bem avaliado, se a economia vai mal, o governo é mal avaliado e o eleitor vota contra ele.

A hipótese de "voto econômico" é considerada no modelo em função dos gastos do governo em educação e saúde. Estes gastos captam a ajuda econômica que o município recebe de esferas superiores (governos do estado e federal).

O modelo estimado considera a participação relativa dos votos do Partido Verde (PV) na eleição presidencial do ano de 2010 no estado do Paraná por município (i). Os votos são explicados pelo conjunto de variáveis explicativas: a) PIB (per capita); b) grau de urbanização (urb); c) Índice IPARDES de Desenvolvimento Municipal - IPDM; d) Despesa municipal em educação (DespE); e) Despesa municipal em saúde (DespS); f) Número de matrículas $(M) ; \mathrm{g})$ Número de eleitores $(E)$.

As variáveis sócio-econômicas como PIB per capita e IPDM buscam capturar a relação entre o voto e o desempenho da renda mais elevada. As variáveis de grau de urbanização e número de leitores buscam capturar o que Bohn (2008) denominou de modernização (urbanização). O número de matrículas é uma Proxy para o número de eleitores jovens, mais propensos para a questão ambiental e feminista presentes na candidatura do PV.

Por fim, a despesa municipal em saúde e educação captura a idéia de voto econômico. Se o governo gasta mais no ano de eleição, a sensação de bemestar aumenta e a propensão de votar a favor do governo (o que significa não votar na legenda do PV).

A variável dependente participação dos votos no PV (Votos) está em valores percentuais e consiste no resultado final divulgado pelo Tribunal Regional Eleitoral nas eleições presidenciais de primeiro turno no ano de 2010.

As demais variáveis são do Instituto Paranaense de Desenvolvimento Econômico e Social (IPARDES). Onde o PIB é per capita e está em valores de moeda corrente para o ano de 2007. O grau de urbanização mede a participação relativa da população urbana no total da população do município e está na forma percentual para o ano de 2007. O Índice IPARDES de Desenvolvimento é a medida do IDH por município do estado no ano de 2007 e envolve a média geral final do indicador ${ }^{4}$. As despesas municipais em educação e saúde estão em valores de moeda corrente e consideram as despesas no ano de 2009. O número de matrículas considera o número total de alunos matriculados no ensino regular no ano de 2009, o que capta o número de jovens, mais atraídos

5 O IDH é a média entre os indicadores de saúde, educação e renda. Ver o estudo da United Nations Development Programme (1990) para a referência metodológica. 
pela causa ambiental 5 . O número de eleitores considera o número total de eleitores aptos a votar na eleição do ano de 2010.

Todas as variáveis são da última versão divulgada pelo IPARDES e são formuladas na seguinte forma:

$$
\begin{aligned}
\operatorname{Votos}_{\mathrm{i} 2010}=\alpha_{0}+\alpha_{1} P_{1 B_{i 2007}}+ & \alpha_{2} U r b_{i 2007}+\alpha_{3} I P D M_{i 2007}+\alpha_{4} D e s p E_{i 2009}+ \\
& \alpha_{5} D e s p S_{i 2009}+\alpha_{6} M_{i 2009}+\alpha_{7} E_{i 2010+} e_{i}(1)
\end{aligned}
$$

Os resultados estimados são apresentados na tabela a seguir.

TABELA 1. RESULTADOS DOS VOTOS NO PARTIDO VERDE NA ELEIÇÃO

\begin{tabular}{|c|c|c|}
\hline Variável & Modelo I & Modelo II \\
\hline Constante & $\begin{array}{l}2,126^{\mathrm{NS}} \\
(1,345)\end{array}$ & $\begin{array}{l}2,221^{* *} \\
(4,201)\end{array}$ \\
\hline PIB & $\begin{array}{l}0,137^{* *} \\
(3,354)\end{array}$ & $\begin{array}{c}0,079^{*} \\
(1,862)\end{array}$ \\
\hline Urbanização & $\begin{array}{l}0,402^{* *} \\
(9,539)\end{array}$ & $\begin{array}{c}0,42^{* *} \\
(10,722)\end{array}$ \\
\hline IPDM & $\begin{array}{c}-0,001^{\mathrm{NS}} \\
(-0,016)\end{array}$ & \\
\hline Despesas em Educação & $\begin{array}{c}-1,00^{* *} \\
(-3,186)\end{array}$ & $\begin{array}{l}-0,817^{* *} \\
(-2,688)\end{array}$ \\
\hline Despesas em saúde & $\begin{array}{c}-0,591^{* *} \\
(-2,8)\end{array}$ & NS \\
\hline Matrículas & $\begin{array}{l}1,903^{* *} \\
(7,028)\end{array}$ & $\begin{array}{c}3,79^{* * *} \\
(6,919)\end{array}$ \\
\hline Eleitores & & $\begin{array}{l}-2,635^{* *} \\
(-4,187)\end{array}$ \\
\hline $\mathrm{F}$ & 61,987 & 78,444 \\
\hline $\mathrm{R}^{2}$ & 0,493 & 0,505 \\
\hline $\mathrm{R}^{2}$ ajustado & 0,485 & 0,499 \\
\hline
\end{tabular}
PRESIDENCIAL NOS MUNICÍPIOS DO ESTADO DO PARANÁ NO ANO DE 2010

* significativo a 10\%, ${ }^{* *}$ significativo a 1\%, ns - não significativo. Valores do teste T em parênteses. FONTE: elaboração própria. 
As duas estimativas realizadas consideram que o grau de urbanização, a renda (PIB per capita) e o número de matrículas no ensino regular são positivamente relacionadas com o voto no Partido Verde nos municípios paranaenses. Na realização da primeira estimativa, verificou-se que o índice IPARDES de Desenvolvimento Municipal era estatisticamente não significativo. O Número de Eleitores e o valor da Despesa em Saúde não puderam ser estimados na mesma equação, onde à introdução do Número de Eleitores (com sinal negativo e estatisticamente significativo) deixou à variável Despesas com Saúde não significativa (sem a primeira, esta apresentava sinal negativo e com significância estatística). Neste sentido, percebe-se que as duas variáveis apresentam correlação de o,986: o Número de Eleitores mostra o tamanho do município, este tamanho está relacionado com o valor das Despesas em Saúde. Portanto, o tamanho do município é um indicador de seu poder econômico e não do seu grau de urbanização como identificado anteriormente ${ }^{6}$.

As variáveis estimadas Despesas em Saúde, Despesas em Educação e N. ${ }^{\circ}$ de Eleitores são estatisticamente significativas e com sinal negativo em relação ao percentual de votos no PV nos municípios paranaenses no ano de 2010.

De forma geral, municípios com maior renda e nível de urbanização, bem como maior número de estudantes (que são jovens) apresentam maior probabilidade de votos no PV. A renda maior está relacionada com a característica urbana e com melhores índices de educação.

O tamanho do município, verificado por meio do número de eleitores, responde negativamente à participação de votos no PV. Neste sentido, municípios maiores geram percentuais menores de votos no partido ${ }^{7}$. Este resultado é, a princípio, divergente. Os municípios maiores apresentam maior nível de renda, urbanização e população com maior escolaridade, o que aumentaria o percentual de votos no PV.

Neste sentido, percebe-se uma distribuição quadrática no tamanho dos municípios paranaenses em função dos votos no PV. Esta hipótese foi testada no seguinte modelo:

$$
P V_{\text {i2010 }}=\alpha_{0}+\alpha_{1} E_{i 2010}+\alpha_{2} E^{2}{ }_{i 2010}+e_{i}
$$

O resultado estimado mostra que o tamanho do município, medido em função do número de eleitores, é uma parábola com concavidade para baixo ( $U$ invertido).

A distribuição quadrática apresentou os seguintes resultados:

7 O tamanho do município é o indicador de distribuição de recursos das demais esferas do governo para atender o maior número possível de eleitores.

8 Apesar do número total de votos ser maior. 
TABELA 2. RESULTADOS DO VOTO NO PV NOS MUNICÍPIOS EM FUNÇÃO DO NÚMERO DE ELEITORES

\begin{tabular}{lc}
\hline \multicolumn{1}{c}{ Variável } & Resultados estimados \\
\hline Coeficiente linear & $7,6793^{* * *}$ \\
& $(40,54)$ \\
$E$ & $0,00016^{* *}$ \\
& $(13,91)$ \\
$E^{2}$ & $-0,000000000196^{* * *}$ \\
& $(-10,67)$ \\
\hline $\mathrm{F}$ & 116,38 \\
$\mathrm{R}^{2}$ & 0,3761 \\
$\mathrm{R}^{2}$ ajustado & 0,3729 \\
\hline
\end{tabular}

* significativo a 10\%, ${ }^{* *}$ significativo a $1 \%$, ns - não significativo. Valores do teste $\mathrm{T}$ em parênteses.

FONTE: elaboração própria.

Com o aumento do tamanho do município, a participação de votos no PV se eleva, até um tamanho máximo, a partir deste ponto, o aumento do tamanho do município reduz a participação dos votos no PV. Neste sentido, municípios pequenos ou muito grandes (com periferias) apresentam eleitores com menor perspectiva de renda e escolaridade, o que reduz o desempenho do PV nestes municípios e os sujeita mais à política de distribuição de recursos do governo, ou seja, o voto econômico torna-se mais fácil.

Os resultados originais da equação (1) estimados em relação à educação, o número de matrículas explicou positivamente a participação nos votos do PV. Todavia, a despesa com educação, assim como a despesa do município em saúde, respondeu negativamente ao percentual de votos no partido. As despesas do município em educação e saúde, em valores de moeda corrente, são relacionadas com o tamanho do município e, assim como o número de eleitores, mostram menor participação do partido nos municípios maiores. Este resultado mostra que a política de distribuição de recursos dos governos nas diferentes esferas, privilegia os municípios maiores (com mais eleitores) e gera um efeito de votação em partidos de situação. Este resultado pode ser confirmado pelas estimativas da tabela 2 a seguir. 
TABELA 3. RESULTADO DA DESPESA EM EDUCAÇÃO E SAÚDE EM FUNÇÃO DOS VOTOS NO PV E NA RENDA DOS MUNICÍPIOS PARANAENSES - 2010

\begin{tabular}{lcc}
\hline \multicolumn{1}{c}{ Variável } & Votos no PV & Renda per capita \\
\hline Intercepto & $11,935^{* * *}$ & $6759,25^{* *}$ \\
& $(14,61)$ & $(5,07)$ \\
DespE/E & $-0,0024^{\mathrm{ns}}$ & $1,351^{\mathrm{ns}}$ \\
& $(-1,59)$ & $(0,54)$ \\
DespS/E & $0,0005^{\mathrm{ns}}$ & $0,9548^{\mathrm{ns}}$ \\
& $(0,4957)$ & $(0,61)$ \\
DespE/M & $-0,0007^{\mathrm{ns}}$ & $1,3819^{\mathrm{ns}}$ \\
& $(-0,66)$ & $(0,82)$ \\
$\mathrm{F}$ & 5,19 & 3,62 \\
$\mathrm{R}^{2}$ & 0,038939 & 0,027461 \\
$\mathrm{R}^{2}$ ajustado & 0,03145 & 0,019883 \\
\hline
\end{tabular}

* significativo a 10\%, ** significativo a 1\%, ns - não significativo. Valores do teste T em parênteses.

FONTE: elaborado pelo autor.

Nas novas regressões apresentadas na tabela 3, foram definidos alguns indicadores relativos como variáveis independentes. Para tanto, o valor das despesas municipais em educação e saúde foram divididas pelo número de eleitores, o que pode ser definido com a despesa média em educação e saúde por eleitor no município ( (DespE/E e DespS/E, respectivamente), por fim o valor das despesas em educação foi dividido pelo número de matrículas, o que pode ser definido com um indicador de despesa média em educação por aluno matriculado (DespE/M). Estes indicadores foram utilizados para explicar a participação nos votos do PV e na renda per capita nos municípios.

Os resultados mostram que a participação dos votos do PV e a renda dos municípios paranaenses não podem ser explicadas pela despesa média em educação e saúde por eleitor, tão pouco pelo valor de despesa média em educação por aluno matriculado no ensino regular.

Os resultados não significativos estatisticamente indicam que as despesas municipais em saúde e educação não estão relacionadas com a renda e conseqüentemente com os votos no PV. Elas seguem a importância do município em função do tamanho, localização e poder de barganha política e não ao perfil sócio-econômico do município, fato que retira destas variáveis o poder de explicação dos votos do PV, apesar de serem variáveis ligadas à qualidade de vida e ao desenvolvimento econômico, mas que não seguem esta relação de perto, em função de políticas de necessidade de distribuição de renda ou eleitorais mesmo e de serem variáveis sócio-econômicas que surtem efeito apenas no longo prazo, por meio da mudança no perfil do eleitorado. 
Neste raciocínio, as despesas em saúde e educação servem como reserva de votos em partidos tradicionais nos dias atuais, todavia, com o tempo, dada a capacidade de distribuição de renda e elevação do desenvolvimento nos municípios, estas despesas ao elevarem a renda determinarão o crescimento da participação nos votos de partidos que apresentem candidatos envolvidos com as preocupações da sociedade moderna, como o PV.

\section{Conclusão}

Este artigo analisou o impacto de variáveis econômicas no processo de escolha do eleitor na eleição presidencial de 2010 nos municípios paranaenses. As variáveis econômicas escolhidas se basearam na revisão de literatura sobre a transformação dos movimentos ambientalistas em partidos verdes nos países desenvolvidos. Neste sentido, verificou-se que a renda elevada e o maior nível educacional eram fatores presentes no eleitorado verde.

O Brasil ainda caminha para a consolidação de seus movimentos ambientalistas. A escolha do estado do Paraná se deu em função da posse dos dados, a generalização das conclusões alcançadas para todo o país não é aconselhável, mas aponta uma tendência.

Primeiramente verificou-se que os municípios com maior número de jovens estudantes (matrículas no ensino regular), com maior taxa de urbanização e renda per capita apresentaram maior taxa relativa de votos no PV na eleição presidencial de 2010. Este fato aponta para a relação entre o nível sócio-educacional e econômico, o grau de urbanização reflete estes dois pontos: os municípios com maior população urbana são mais ricos e conseqüentemente, com maior nível educacional no seu eleitorado, além da maior presença de jovens eleitores.

Em segundo lugar verificou-se que as transferências públicas em educação e saúde são inversamente proporcionais aos votos no PV na eleição presidencial de 2010 nos municípios paranaenses. Neste sentido, quanto mais recursos externos o município recebe, menor o descontentamento do eleitorado. Percebe-se que a população com menor poder aquisitivo e escolaridade depende mais das transferências governamentais externas (em saúde e educação), certamente porque impactam mais as suas condições de vida.

Estudos futuros podem explorar as causas do descontentamento do eleitor com o perfil dos candidatos e partidos políticos. Além de relacionarem a aversão à corrupção, segurança e outras variáveis que se aproximam mais do perfil do eleitorado com maior nível sócio-econômico e do eleitorado jovem. 


\section{Referências bibliográficas}

BALBACHEVSKY, E; HOLZHACKER, D. (2004). "Identidade, oposição e pragmatismo: o conteúdo estratégico da decisão eleitoral em 13 anos de eleições”. Opinião Pública, vol. 10(2); p. 242-253.

BOHN, SR. (2008). "Mulher para presidente do Brasil? Gênero e política na perspectiva do eleitor brasileiro". Opinião Pública, vol. 14(2); p. 352-379.

BORBA, J. (2005). “Cultura política, ideologia e comportamento eleitoral: alguns apontamentos teóricos sobre o caso brasileiro”. Opinião Pública, vol. 11(1); p. 147-168.

CARREIRÃO, Y. (2004). “A eleição presidencial de 2002: uma análise preliminar do processo e dos resultados eleitorais”. Revista de Sociologia Política, vol. 22; p. 179-194.

CARREIRÃO, Y. de S. (1999). “Avaliação do governo e voto econômico”. Lua Nova, n. ${ }^{\circ} 48 ;$ p. $213-229$.

CASTELLS, M. (1999). O poder da identidade. São Paulo: Paz e Terra.

FINAMORE, C.; CARVALHO, J. de (2006). Mulheres candidatas: relações entre gênero, mídia e discurso. Estudos Feministas, vol. 14(2); p. 347-362.

GORE, A. (2008). A terra em balanço: ecologia e o espírito humano. São Paulo: Gaia.

IPARDES (2012). Banco de dados do Estado do Paraná. URL [on-line]: http://www.ipardes.gov.br

MANIN, B.; PRZEWORSKI, A.; STOKES, S. (2006). “Eleições e representação”. Lua Nova, vol. 67; p. 105-138.

NOSTY, B. D. (2008). “O meio [ambiente] é a mensagem: estratégias de comunicação para uma inovação sustentável”. MELO, J. M. de (2008). Mídia, ecologia e sociedade. São Paulo: Intercom; p. 35-50.

RAMPAZZO, S. E. (2002). “A questão ambiental no contexto do desenvolvimento sustentável”. In: BECKER, D. F. (2002). Desenvolvimento sustentável: necessidade e/ou possibilidade? Santa Cruz do Sul: Edunisc; p. 161-190.

SACHS, I. (1986). Ecodesenvolvimento: crescer sem destruir. São Paulo: Vértice.

THOMAS, V. et al. (2002). A qualidade do crescimento. São Paulo: Editora Unesp.

TOFFLER, A. (2003). Powershit: as mudanças do poder. Rio de Janeiro: Record.

UNITED NATIONS DEVELOPMENT PROGRAMME. (1990). Human development report 1990. New York: Oxford University Press.

VEIGA, L. F. (2007). “Os partidos brasileiros na perspectiva dos eleitores: mudanças e continuidades na identificação partidária e na avaliação das principais legendas após 2002”. Opinião Pública, vol. 13(2); p. 340-365.

VIEIRA, L. (2001). Os argonautas da cidadania: a sociedade civil na globalização. Rio de Janeiro: Record.

VINCENT, A. (1995). Ideologias políticas modernas. Rio de Janeiro: Jorge Zahar Editor. 


\section{Anexo}

QUADRO 1. ESTATÍSTICA DESCRITIVA

\begin{tabular}{|l|r|r|r|r|r|}
\hline & N. ${ }^{o}$ & Mínimo & \multicolumn{1}{c|}{ Máximo } & \multicolumn{1}{c|}{ Media } & \multicolumn{1}{c|}{ Desvio típ. } \\
\hline Votos & 399 & 2,67 & 26,73 & 8,95 & 4,11 \\
PIB & 399 & 4423,00 & 86736,00 & 10947,84 & 6659,17 \\
Urbanização & 399 & 8,44 & 100,00 & 65,48 & 20,79 \\
IPDM & 399 & 0,34 & 0,81 & 0,56 & 0,05 \\
DespE & 390 & 975433,17 & 631553372,92 & 8596891,61 & 34431230,44 \\
DespS & 389 & 210032,42 & 821442774,64 & 9041978,33 & 45712234,67 \\
Matrículas & 399 & 364,00 & 403921,00 & 6303,12 & 22747,30 \\
Eleitores & 399 & 680,00 & 698545,00 & 9802,60 & 38469,47 \\
N. ${ }^{\circ}$ válido & 389 & & & & \\
\hline
\end{tabular}

FONTE: elaborado pelo autor.

Recebido em: 04 de agosto de 2011

Aceito em: 17 de agosto de 2012 